\title{
Adjustment to traumatic spinal cord injury. A longitudinal study of self-reported quality of life
}

\author{
R Stensman MD
}

Assistant Professor, Chief Physician, Department of Rehabilitation Medicine, Uppsala University, Akademiska sjukhuset, S-751 85 Uppsala, Sweden.

In order to meet a long expressed need for a longitudinal study on personal adjustment to traumatic spinal cord injury, 17 consecutively treated persons with complete traumatic spinal cord injury were interviewed $0.5-5$ years after the injury on six occasions, with a total of 102 interviews. The variables studied were age at injury, social status, the cause of the accident, spinal level of injury and physical complications. The subjective quality of life (QOL) was reported on a $0-10$ scale at all interviews and showed four patterns during the 5 year period. Five subjects reported that they were coping very well, with an almost unchanged QOL after the injury. Six reported good coping after an initially low QOL in the first years. Two subjects reported an unstable QOL, and four persons reported a continually low QOL without improvement. Variables related to unsatisfactory coping were severe pain, age above 35 years at the time of trauma, and being blameless for the accident.

Keywords: spinal cord injuries; psychological adjustment; sociological adjustment; quality of life.

\section{Introduction}

Knowledge about adjustment to traumatic spinal cord injury (SCI) is incomplete, one possible reason being that the coping process is specific for each individual and is also dependent on several different factors. Important surveys on this subject have been presented. ${ }^{1-4}$

The coping process among persons with SCI has been described in relation to a number of variables, including age at onset, ${ }^{5}$ duration of disability, ${ }^{5}$ gender,, 6 background of the trauma, ${ }^{7}$ social situation, ${ }^{8}$ level of injury, ${ }^{9,10}$ physical problems including pain, ${ }^{1}$ personality ${ }^{1}$ including sensationseeking behaviour, ${ }^{11}$ and locus of control. ${ }^{1}$ The previously cherished 'stage theory' has been challenged ${ }^{12}$ and the proportion of patients with depression after SCI has been found to be relatively low ${ }^{10,12-14}$ and also overestimated by the rehabilitation staff. ${ }^{15}$ In a few reported studies concerning adjustment to SCI, a longitudinal approach has been used. ${ }^{10,16}$ The quality of life has been investigated both among persons with severe disability of movement, ${ }^{17}$ and among those with traumatic spinal cord injuries. ${ }^{1,18-22}$

The aim of the present longitudinal study was to examine the adjustment of persons with complete, irreversible traumatic spinal cord injury during a period of 5 years after the injury, and their self-reported quality of life.

\section{Subjects and methods}

All persons aged 18-75 years who had sustained a complete, irreversible traumatic spinal cord injury between August 1985 and September 1987 in the regions of Stockholm and Uppsala (approximately 3 million inhabitants) were contacted. There were 19 such persons; two of them could not take part in the study: one woman went back to Africa and one man with alcohol abuse refused to be interviewed. The remaining 17 
persons were aged $18-55$ years at the time of the injury. Fifteen were men and two were women. Ten were tetraplegic and seven paraplegic. The cause of the SCI was a traffic accident (9), fall from a height (4), diving (2), riding (1) and an accident at work (1). The SCI was not associated with a head injury in any of the subjects.

The 17 subjects were interviewed personally by the author 6 months and 1,2, 3, 4 and 5 years after the injury. Some interviews were conducted by telephone, but these were usually 4 years after the SCI. The interviews were semistructured and included questions about medical, psychological and social variables, activities of daily living (ADL) function and quality of life. The term 'quality of life' (QOL) cannot be distinctly defined. In this study the term is understood to be a keynote in an individual's life, which is influenced by several factors including psychological and physical conditions as well as relations to other people and society. The concepts of QOL and of 'overall life satisfaction' are essentially congruous. Thus QOL is something relative which the individual measures in relation to his or her needs and expectations.

QOL over the last 6 months was estimated subjectively by the 17 subjects on an imaginary scale of $0-10$. This method was used by the author in a previous study and is described in that report. ${ }^{17}$ The assessment of QOL was made by the subjects on the basis of their own assumptions, perceptions, goals and values. In the instructions 0 corresponded to the lowest QOL and 10 to the highest QOL. At each of the six interviews the subjects were asked to rate their QOL before the injury in the same way as above. The mean value from these six ratings was calculated and is presented as an average level.

\section{Results}

The individual, longitudinally reported levels of the quality of life of the 17 persons are presented in Figures 1-4. From a visual inspection of the QOL patterns, four groups were identified, and in allocating people to

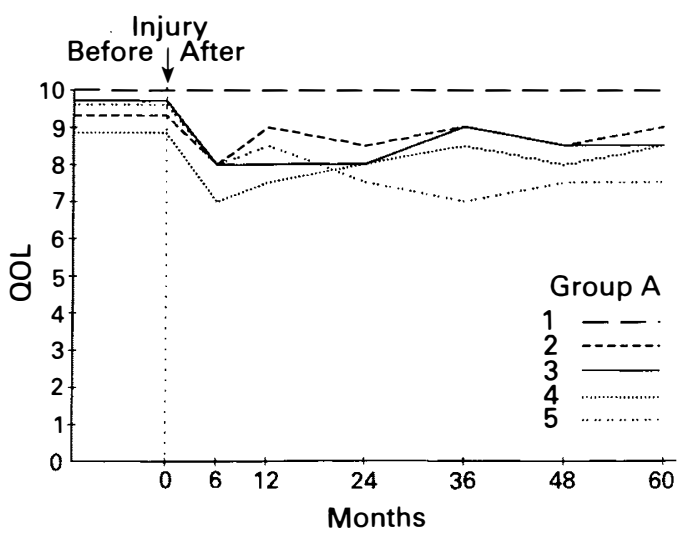

Figure 1 Group A $(n=5)$ representing good coping-stable, showing the self-reported QOL before and 6-60 months after traumatic SCI $(10=$ highest $\mathrm{QOL}, 0=$ lowest $\mathrm{QOL})$.

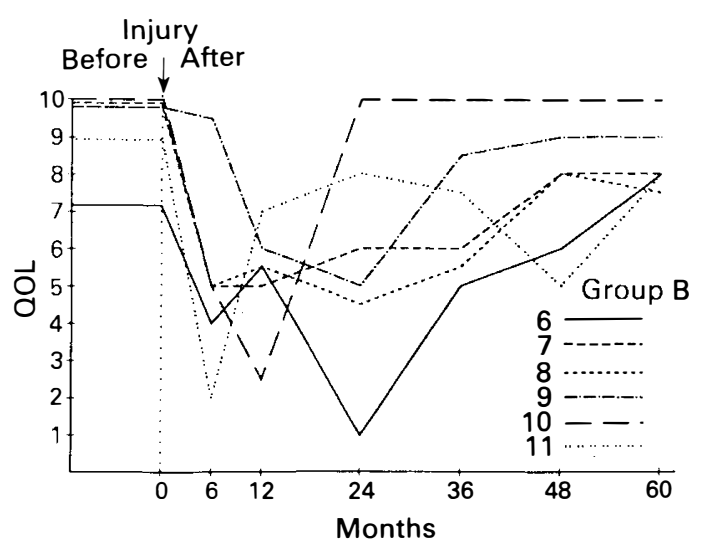

Figure 2 Group B $(n=6)$ representing good coping after low QOL, showing the selfreported QOL before and 6-60 months after traumatic SCI $(10=$ highest $\mathrm{QOL}, 0=$ lowest QOL).

the different groups a global judgement of the person's situation was also taken into account, using information obtained during the series of interviews, including body language and standard of living. During the study the author became well acquainted with the individual subjects and this was also of importance in the allocation into groups. The four groups were designated as follows. 


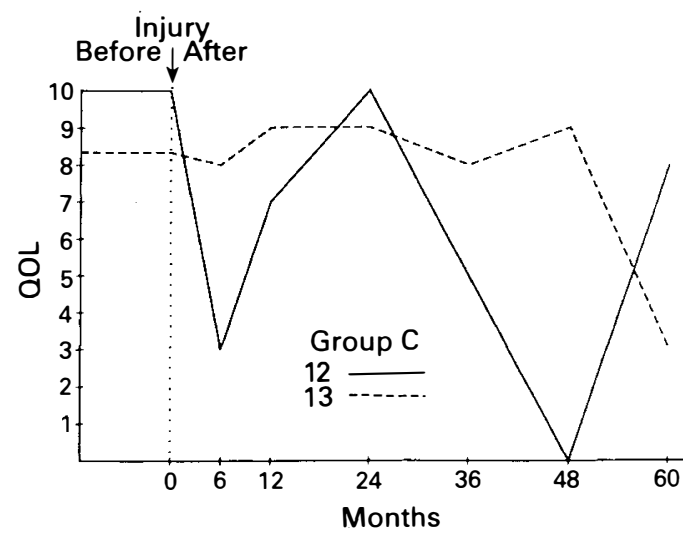

Figure 3 Group C $(n=2)$ representing 'unstable' coping, showing the self-reported QOL before and 6-60 months after traumatic SCI $(10=$ highest $\mathrm{QOL}, 0=$ lowest $\mathrm{QOL})$.

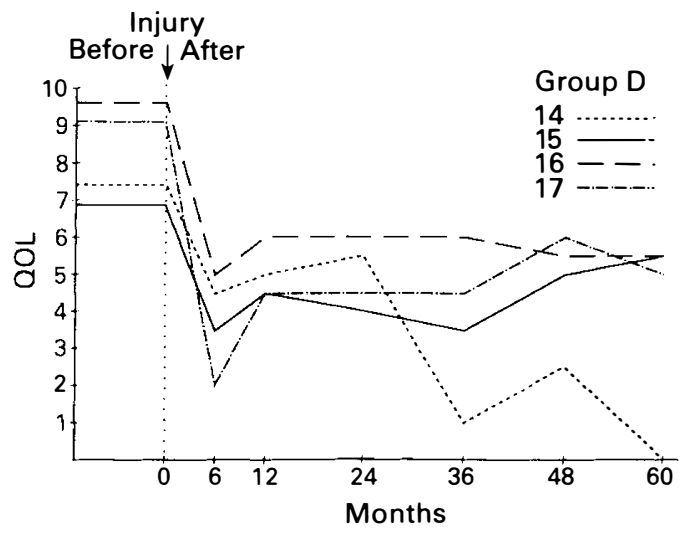

Figure 4 Group D $(n=4)$ representing unsatisfactory coping, showing the self-reported QOL before and 6-60 months after traumatic SCI $(10=$ highest $\mathrm{QOL}, 0=$ lowest $\mathrm{QOL})$.
A Good coping-stable $(n=5)$
B Good coping after initially low QOL $(n=6)$
C 'Unstable' coping $(n=2)$
D Unsatisfactory coping $(n=4)$.

In this paper the term 'coping' is used synonymously with 'adjustment'. It is difficult to rate. In this study the subjective report of QOL was an important factor in the estimation of coping, but the global judgement described above was also taken into account.
In Table I some characteristics of the 17 subjects are presented, with the subjects grouped in the same way as above.

The five subjects in group A (good coping, stable) reported an essentially unchanged QOL during the period $0.5-5$ years after the injury. Three had paraplegia, and two tetraplegia. These five subjects reported no physical complications or pain. Four of the five had returned to work 5 years after the injury.

The six subjects in group B (good coping after initially low QOL) reported a low QOL at the interviews $0.5,1$ and 2 years after the SCI, but 3-5 years after the trauma they reported it to be at almost the same level as before the accident. These six men were fairly young. Four had returned to work. Five had tetraplegia, two had moderate pain and one had bowel problems.

The two men in group C (unstable, fairly good coping) reported different values of QOL at different times. The older of the two men started as in group A, but pain and other problems led to a report on a low QOL at the interview 5 years after the SCI. The younger man started as in group B, but 3 and 4 years after the SCI he was suffering from pain, which was not the case at the interview 5 years after the SCI. Neither of the two men was at work. Both were ADL-dependent in their daily life.

The four persons in group D (unsatisfactory coping) reported a continuously low QOL without improvement; they were older (mean age at the accident 43 years). Two of them were working 5 years after the injury. Two subjects had tetraplegia. Two had very severe pain below the injured level and the other two had moderate pain.

The 17 subjects were asked about psychiatric problems. Seven reported no problems at all, four reported no psychiatric problems but had short periods of grief and bitterness. Some depression and anxiety, mainly 2-4 years after the SCI, were reported by three persons and severe depression was reported by another three persons, two from group D. One person periodically abused analgesics. None of these subjects was treated in a psychiatric ward.

Fourteen persons reported positive factors that had resulted from the SCI: 'learnt 
Table I Some characteristics of 17 subjects with traumatic spinal cord injury (SCI) interviewed on six occasions $0.5-5$ years after the SCI

\begin{tabular}{|c|c|c|c|c|c|c|c|c|c|c|c|c|c|c|c|c|c|}
\hline & \multicolumn{5}{|c|}{$\begin{array}{c}\text { Group A } \\
\text { Good coping, } \\
\text { stable }\end{array}$} & \multicolumn{6}{|c|}{$\begin{array}{c}\text { Group B } \\
\text { Good coping after } \\
\text { low QOL }\end{array}$} & \multicolumn{2}{|c|}{$\begin{array}{l}\text { Group C } \\
\text { Unstable } \\
\text { coping }\end{array}$} & \multicolumn{4}{|c|}{$\begin{array}{c}\text { Group D } \\
\text { Unsatisfactory } \\
\text { coping }\end{array}$} \\
\hline & 1 & 2 & 3 & 4 & 5 & 6 & 7 & 8 & 9 & 10 & 11 & 12 & 13 & 14 & 15 & 16 & 17 \\
\hline Age at injury & 51 & 27 & 21 & 22 & 20 & 20 & 18 & 36 & 37 & 31 & 23 & 22 & 44 & 54 & 46 & 36 & 35 \\
\hline Sex & M & $\mathrm{F}$ & M & M & M & M & M & M & M & M & M & $\mathrm{M}$ & M & M & $\mathrm{F}$ & M & M \\
\hline Spouse/Parents/Alone $=\mathrm{S} / \mathrm{P} / \mathrm{A}$ & $\mathrm{S}$ & $\mathrm{S}$ & $\mathrm{P} / \mathrm{S}$ & $\mathrm{P} / \mathrm{A}$ & $\mathrm{P}$ & $\mathrm{A} / \mathrm{S}$ & $\mathrm{P}$ & A & $\mathrm{S}$ & $\mathrm{S} / \mathrm{A}$ & $\mathrm{S}$ & $\mathrm{A} / \mathrm{S}$ & A & $\mathrm{S}$ & A & A & $\mathrm{S}$ \\
\hline College education before SCI & & & & & & & & & & & + & & & & + & & + \\
\hline Employment/studies after SCI & + & & + & + & + & + & & + & + & & + & & & & + & & \\
\hline Leisure of importance & + & & + & + & & & & & + & & & & & & + & & + \\
\hline Victim at injury & + & & & + & & & + & & & + & & & & + & + & + & + \\
\hline Level of injury Tetra/Para & $\mathrm{P}$ & $\mathrm{P}$ & $\mathrm{T}$ & $\mathrm{P}$ & $\mathrm{T}$ & $\mathrm{P}$ & $\mathrm{T}$ & $\mathrm{T}$ & $\mathrm{T}$ & $\mathrm{T}$ & $\mathrm{P}$ & $\mathrm{T}$ & $\mathrm{P}$ & $\mathrm{T}$ & $\mathrm{P}$ & $\mathrm{P}$ & $\mathrm{T}$ \\
\hline ADL-dependence & & & + & & + & & + & + & + & + & & + & + & + & + & & + \\
\hline Severe pain & & & & & & & & & $(+)$ & & $(+)$ & $(+)$ & $(+)$ & + & + & & $(+)$ \\
\hline Other physical complication & & & & & & & & & & & $(+)$ & & $(+)$ & & & & $(+)$ \\
\hline Depression after SCI & $(-)$ & - & - & - & - & $(+)$ & $(+)$ & $(-)$ & $(-)$ & - & + & $(-)$ & - & $(+)$ & + & + & - \\
\hline Susceptibility to stress & & & & & & & & & & & & & & + & & ++ & \\
\hline Adaption of others to the SCI & + & Var & + & + & Var & $?$ & + & Var & $?$ & $?$ & + & + & Var & Var & + & $?$ & $?$ \\
\hline Handicap sport participation & + & & + & & & $(+)$ & $(+)$ & $(+)$ & & & $(+)$ & $(+)$ & & & $(+)$ & & \\
\hline Spouse inform insufficient & & & & & & & & + & & + & + & $(+)$ & & & & & \\
\hline Nonacceptance of disability & & & & & & & + & & & & + & & & & & & \\
\hline Time passing slowly after SCI & & & & & & & + & & & & + & & & & & & \\
\hline
\end{tabular}

$(+)=$ moderate $;(-)=$ slight .

Var = varied; ? = did not know. 
what is important in life', 'humility, simplicity' $(n=9)$, positive contacts with new persons they had met after the SCI $(n=7)$, positive personality change $(n=5)$, less stress $(n=4)$. One person sometimes reported more than one positive factor. Among the three subjects who did not report any positive factor, two belonged to the group with unsatisfactory coping. Negative factors associated with the SCI were reported by all subjects: to be dependent, problems with bladder, pain, not being able to do things 'at once', being unable to walk, use stairs, dance, be out in the countryside, cycle, ski and fish. Two persons had problems with limited sexual activities and one suffered from spasticity.

Three years after the SCI the subjects were asked about factors that they considered would raise their QOL. Five answered that driving a car would be one factor. Other factors reported were walking and moving around better $(n=4)$, improved bladder function $(n=3)$, improved function in the arms $(n=3)$, improved defecation $(n=2)$, less pain $(n=2)$, and lower body weight $(n=2)$. Four persons mentioned 'having a partner and/or children', three said 'work' and two stated 'better living'.

Three divorces took place during the interview period and there were four marriages. All divorces were in group B. In the opinion of seven of the subjects, the information given to the spouse was sufficient, whereas four considered that it was not sufficient; the question was not relevant for five subjects, and one person did not know. The adaptation of the spouses seemed to follow the same pattern as that of the interviewed person.

At the interview 5 years after the SCI the subjects were asked about factors which they considered had a positive influence on the adaptation process. Sixteen subjects answered. The most common answers $(n=9)$ were personality variables (obstinacy and 'being mainly positive'). Others mentioned 'security in getting help with all sorts of problems' $(n=7)$, support from the spouse $(n=5)$, good contact with friends $(n=3)$, absence of pain $(n=3)$, to have work $(n=2)$, contact with a non-profit- making association of patients with traumatic spinal cord injury, 'rekryteringsgruppen' that helps those with new trauma of the spinal cord $(n=2)$ and positive experiences from earlier life $(n=2)$. One person held a 'no choice' attitude and another stated that 'time heals all wounds'.

The 'most difficult time' after the SCI was the first 7 months, as was reported by 14 subjects. The other three persons considered the first year, the first 2 years and the first 3 years respectively, most difficult. Five persons found that the first two months were the most difficult time.

The 17 persons were asked at the interviews 1 and 2 years after the SCI if they had felt that 'life was not worth living'. Four answered no and five said that they had had such thoughts at the very beginning. Four thought that 'life was not worth living' at both interviews (two each in groups B and D), three at the interview 1 year after the SCI and one at the interview 2 years after the SCI. One person had had a serious suicide attempt shortly after leaving hospital 3 months after the SCI.

All 17 subjects reported that they had 'good control' of their lives, and 'susceptibility to stress' was reported by only two persons, both in group D. Only two subjects stated that time had passed slowly since the SCI.

The subjects were asked how they considered that other people with SCI had adapted to their (the other person's) situation. Seven subjects thought that they had adapted well, five that it varied and five that they did not know.

Handicap sport was practised by two subjects in group A and to a lesser extent by some subjects in the other groups. Leisure activities of importance were fairly common in the two extreme groups (A and D). New hobbies since the SCI (handicap sport excluded) were uncommon. They were more frequent in the group with unsatisfactory coping.

Regarding the subjects' experiences of other people's attitudes towards their disability after the SCI, only two expressed major or moderate problems. One of them had lack of respect at work and the other felt that people pitied him. The other 15 
subjects found this to be a minor or negligible problem.

\section{Discussion}

The number of subjects with SCI in this study is small and the study is of a hypothesis-generating character. The subjects represent a homogeneous group with complete lesions and no return of activity below the lesion. They live in a country with high financial security for people with disabilites.

Measuring the quality of life is difficult, and its evaluation has to be subjective. QOL is individual, complex and global. In this paper QOL is used in the sense of 'overall life satisfaction'.

There appears to be four patterns of adjustment to, that is coping with, SCI regarding the quality of life. The grouping is based on visual assessment of the different curves of subjectively reported QOL and all information obtained at the interviews, and there is no sharp demarcation between the groups.

Ages at injury of 35 and above predominated in group D (insufficient coping). In earlier studies ${ }^{1,5}$ it has been shown that a higher age at injury is correlated to difficulties in adjustment. With increasing age there is a loss of energy and it becomes more difficult to adjust to changes in life.

Differences in civil status showed no notable influence on the adjustment process. University education before the SCI was fairly uncommon among the subjects of this study, but did not seem to correlate with their coping. It was found in an earlier study $^{6}$ that injured persons with less education scored lower in adjustment variables than more educated people.

Psychiatric problems of varying degrees were reported by a minority of the subjects, in accordance with findings in studies of the last two decades. There were no signs of reactions related to the 'stage theory'. Twelve of the 17 subjects had felt that 'life was not worth living', which is a much higher incidence than was found in a general population survey in Connecticut in $1974 .{ }^{23}$ The first half-year after the injury was reported to be 'the most difficult time'.
Among the negative aspects of the SCI, problems related to the bladder and bowel were frequently reported. Positive aspects were pointed out by almost all subjects. The importance of good relationships with relatives and friends was frequently mentioned by the subjects.

Regarding the causality of the accident, it has been shown ${ }^{24}$ that those who were actively involved in the accident receive the most favourable ratings in adjustment. In this study the groups with good coping $(A-C)$ showed the highest proportions of persons who had reason to blame themselves for the accident: Group A: 3/5, B: 4/6, C: $2 / 2$ and D: $0 / 4$.

The spinal level of the lesion and the dependence on help in daily living do not seem to influence the adjustment to a spinal cord injury. ${ }^{1,9}$ In this study the proportion of independent paraplegic persons was highest in group A (good coping, stable).

Pain seems to be a great impediment to good adjustment to SCI, as three out of four patients in group D (insufficient coping) had pain, this being very severe in two. This is in agreement with other observations. ${ }^{1,22}$ Other physical complications seem to be of less importance.

In studies of adjustment to traumatic spinal cord injury it is very important to listen directly to the patient him/herself. Discrepancies have been reported between staff members working in SCI rehabilitation centres and persons with SCI regarding their views on symptoms in these persons, eg depression. ${ }^{15}$ In a study in 1976 , Hanson \& Franklin ${ }^{25}$ asked 54 men with SCI to rank the functional losses associated with their injuries. In addition, staff members of a rehabilitation team caring for these patients were asked to give their opinion of the importance of these functional losses to their cord injured patients. The data indicated that contrary to the patients' ranking, the staff tended to overemphasise the importance of normal genital sexual functioning.

An irreversible traumatic spinal cord injury is one of the most serious events that can happen in a person's life. The adjustment requires significant strength on the part of the injured person and much effort 
from people close to him or her and from society. Most persons succeed during the subsequent years in finding a new life with possibilities of realising the quality of life towards which they aim. Further investiga- tions in this personal and complex adaptation process require a keen ear and respect for all individual reports from persons who have had the experience of sustaining a traumatic spinal cord injury.

\section{References}

1 Trieschmann RB (1988) Spinal Cord Injuries: Psychological, Social, and Vocational Rehabilitation. Demos Publications, New York.

2 Trieschmann RB (1992) Psychosocial research in spinal cord injury: the state of the art. Paraplegia 30: 58-60.

3 Whalley Hammell KR (1992) Psychological and sociological theories concerning adjustment to traumatic spinal cord injury: the implications for rehabilitation. Paraplegia 30: 317-326.

4 Frank RG, Elliot TR, Corcoran JR, Wonderlich SA (1987) Depression after spinal cord injury: Is it necessary? Clin Psychol Rev 7: 611-630.

5 Krause JS, Crewe NM (1991) Chronologic age, time since injury, and time of measurement: effect on adjustment after spinal cord injury. Arch Phys Med Rehabil 72: 91-100.

6 Woodrich F, Patterson JB (1983) Variables related to acceptance of disability in person with spinal cord injuries. J Rehabil 49: 26-30.

7 Bulman RJ, Wortman CB (1977) Attributions of blame and coping in the 'real world': severe accident victims react to their lot. J Pers Soc Psychol 35: 351-363.

8 Schultz R, Decker S (1985) Long-term adjustment to physical disabilty: the role of social support, perceived control and self-blame. J Pers Soc Psychol 48: 1162-1172.

9 Nieves CC, Charter RA, Aspinall MJ (1991) Relationship between effective coping and perceived quality of life in spinal cord injured patients. Rehabil Nurs 16: 129-132.

10 Hancock KM, Craig AR, Dickson HG et al (1993) Anxiety and depression over the first year of spinal cord injury: a longitudinal study. Paraplegia 31: 349-357.

11 Mawson AR, Jacobs KW, Winchester Y, Biundo JJ (1988) Sensation-seeking and traumatic spinal cord injury: case-control study. Arch Phys Med Rehabil 69: 1039-1043.

12 Buckelew SP, Frank RG, Elliot TR et al (1991) Adjustment to spinal cord injury: stage theory revisited. Paraplegia 29: 125-130.

13 Richards JS (1986) Psychologic adjustment to spinal cord injury during first postdischarge year. Arch Phys Med Rehabil 67: 362-365

14 Judd FK, Brown DJ, Burrows GD (1991) Depression, disease and disability: application to patients with traumatic spinal cord injury. Paraplegia 29: 91-96.

15 Dijkers M, Cushman LA (1990) Differences between rehabilitation disciplines in views of depression in spinal cord injury patients. Paraplegia 28: 380-391.

16 Krause JS (1992) Longitudinal changes in adjustment after spinal cord injury: a 15-year study. Arch Phys Med Rehabil 73: 564-568.

17 Stensman R (1985) Severe mobility-disabled people assess the quality of their lives. Scand J Rehabil Med 17: 87-99.

18 Fuhrer MJ, Rintala DH, Hart KA et al (1992) Relationship of life satisfaction to impairment, disability, and handicap among persons with spinal cord injury living in the community. Arch Phys Med Rehabil 73: 552-557.

19 Crewe NM (1980) Quality of life - the ultimate goal in rehabilitation. Minnesota Med 63: 586-589.

20 Ray C, West J, (1984) I. Social, sexual and personal implications of paraplegia. Paraplegia 22: 75-86.

21 Carlson CE (1879) Conceptual style and life satisfaction following spinal cord injury. Arch Phys Med Rehabil 60: 346-352.

22 Lundqvist C, Siösteen A, Blomstrand C et al (1991) Spinal cord injuries, clinical, functional, and emotional status. Spine 16: 78-83.

23 Paykel ES, Myers JK, Lindenthal JJ, Tanner J (1974) Suicidal feelings in the general population: a prevalence study. Br J Psychiatry 124: 460-469.

24 Athelstan GT, Crewe NM (1979) Psychological adjustment to spinal cord injury as related to manner of onset of disability. Rehabil Counsel Bull 22: 311-319.

25 Hanson RW, Franklin MR (1976) Sexual loss in relation to other functional losses for spinal cord injured males. Arch Phys Med Rehabil 57: 291-293. 